\title{
Levantamento de leishmaniose visceral em cães de Santa Maria e municípios próximos, Estado do Rio Grande do Sul
}

\author{
A survey of visceral leishmaniasis in dogs from Santa Maria and \\ neighbouring municipalities, State of Rio Grande do Sul \\ Carlos Brisola Marcondes ${ }^{1}$, Claude Pirmez ${ }^{2}$, Eduardo S. Silva ${ }^{3,4}$, Valmir Laurentino-Silva ${ }^{2}$ \\ Mário Steindel ${ }^{1}$, A.J. Santos ${ }^{5}$, H. Smaniotto ${ }^{5}$, C.F.B. Silva ${ }^{4}$, \\ V.F. Schuck Neto ${ }^{5}$ e Alcione Donetto ${ }^{6}$
}

\begin{abstract}
Resumo A partir de relato de diagnóstico de leishmaniose visceral em cinco cães dos municípios de Santa Maria, Itaara e Júlio de Castilhos, no centro do Estado do Rio Grande do Sul, foi realizado levantamento sorológico através de teste de imunofluorescência indireta em sangue obtido em papel de filtro de 40 cães de Santa Maria, 20 de Itaara e 11 de Júlio de Castilhos, em geral relacionados aos cinco cães considerados como positivos. Além destes, foi também examinado o sangue de 44 cães vadios de Júlio de Castilhos, 68 de Cachoeira do Sul e 20 de Caçapava do Sul. Soros fracamente reagentes com títulos $\leq 1: 40$ foram avaliados em ensaios de Ensaio Imuno-enzimático. Amostras de fígado, baço, pulmão e linfonodos de um sexto cão de Santa Maria, considerado como positivo à necropsia, foram examinadas através de histopatologia e PCR. Todos os resultados dos 204 cães foram negativos, indicando que, apesar de não ser impossível a ocorrência de leishmaniose visceral na região, por vários fatores aqui discutidos, ela deve ser pelo menos extremamente rara, sendo necessários estudos mais detalhados do material dos cinco cães tidos como positivos.
\end{abstract}

Palavras-chaves: Leishmaniose visceral. Rio Grande do Sul. Cão. Reservatório. Epidemiologia.

\begin{abstract}
Five dogs from the municipalities of Santa Maria, Itaara and Júlio de Castilhos, in the centre of the Brazilian State of Rio Grande do Sul, were diagnosed as positive for visceral leishmaniasis. A survey was developed by indirect immunofluorescence in blood obtained in filter paper from 40 dogs from Santa Maria, 20 from Itaara and 11 from Júlio de Castilhos. Examined dogs were generally related to those reputedly positive. Besides the above dogs, blood from 44 stray dogs from Júlio de Castilhos, 68 from Cachoeira do Sul and 20 from Caçapava do Sul was also examined. Slightly positive sera $(£ 1: 40)$ were examined with ELISA. PCR and histology was used to examine the liver, spleen, lungs and lymph nodes from a sixth dog considered at necropsy to be positive for visceral leishmaniasis. All results for the 204 dogs were negative. This indicates that visceral leishmaniasis, due to various factors discussed below, is extremely rare in this region. A more detailed exam of the material from the five dogs considered positive is necessary.
\end{abstract}

Key-words: Visceral leishmaniasis. Rio Grande do Sul. Dog. Reservoir. Epidemiology.

A leishmaniose visceral é comum e muito importante no Brasil. Ela ocorre nas regiões nordeste, sudeste, norte e centro-oeste, podendo ser letal mesmo quando tratada, especialmente em crianças desnutridas. O seu vetor principal (Lutzomyia longipalpis) passou a se tornar comum no oeste de São Paulo, mesmo em áreas urbanas ${ }^{5}$, tendo ocorrido vários casos humanos, com óbitos, neste Estado.

\footnotetext{
1. Departamento de Microbiologia e Parasitologia do Centro de Ciências Biológicas da Universidade Federal de Santa Catarina, Florianópolis, SC. 2. Fundação Oswaldo Cruz, Rio de Janeiro, RJ. 3. Centro de Pesquisas Rene Rachou da Fundação Oswaldo Cruz, Belo Horizonte, MG, Fundação Educacional de Divinópolis. 4. Centro de Pós-Graduação e Pesquisa da Universidade do Estado de Minas Gerais, Divinópolis, MG. 5. Secretaria Municipal de Saúde, Santa Maria, RS. 6. Fundação Nacional de Saúde do Rio Grande do Sul.

Endereço para correspondência: Prof. Carlos Brisola Marcondes. Dept ${ }^{\circ}$ Microbiologia e Parasitologia/CCB/UFSC. Campus Trindade, $88040-900$ Florianópolis, SC. Fax: 5548 331-9258.

e-mail-cbrisola@mbox1.ufsc.br

Recebido para publicação em 14/08/2002

Aceito em 10/6/2003
} 
Na região sul, com exceção de dois casos humanos de leishmaniose visceral humana relatados no Paraná ${ }^{4}$, um deles no limite com o Estado de Mato Grosso do Sul ${ }^{4}$, não há relato de casos nos outros dois Estados (Santa Catarina e Rio Grande do Sul).

Foi publicado recentemente um relato do encontro de cinco cães infectados com leishmaniose visceral em Santa
Maria, no centro do Estado do Rio Grande do Sul ${ }^{17}$, com base em necropsia. Este relato, associado ao pouco conhecimento da fauna de flebotomíneos do Estado, à presença de Lutzomyia longipalpis na província argentina contígua de Misiones ${ }^{18}$ e ao grande trânsito de militares na região, alguns dos quais possivelmente transportando cães infectados, motivou o presente levantamento na área.

\section{MATERIAL E MÉTODOS}

Para o diagnóstico sorológico dos animais foram coletadas duas amostras de sangue periférico (orelha) em papel de filtro, de 40 cães do Município de Santa

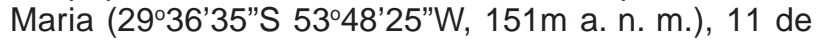

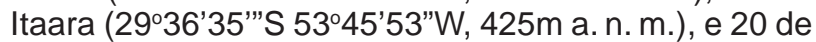
Júlio de Castilhos (29¹3'37" S 5340'54" W, 513m a. n. $\mathrm{m}$.), na maioria provenientes da vizinhança dos cães considerados como positivos. Foram também coletadas amostras de cães vadios dos municípios: Júlio de Castilhos (44), Cachoeira do Sul (3002'21"S 52.53'38”W, 68m a. n. m.) (68) e Caçapava do Sul (30॰30'44"S 5329'29”'W, 444m a. n. m.) (20). As duas amostras de cada cão foram examinadas por Imunofluorescência Indireta, de forma independente (ESS e VLS). Foi utilizada a pesquisa de anticorpos antiLeishmania por imunofluorescência em sangue de todos os animais estudados utilizando Kit IFI - Leishmaniose Canina (Fundação Oswaldo Cruz/Biomanguinhos). Amostras de sangue de cães sabidamente positivos e negativos foram incluídos nos exames, em que a diluição inicial foi de 1:40 e final de 1:640. Soros de cães com títulos de imunofluorescência indireta $(\leq 1: 40)$ foram testados em ensaios de ELISA utilizando antígeno purificado (Fundação Oswaldo Cruz/Biomanguinhos Leishmania major). Blocos de vísceras de um sexto cão, também considerado como sugestivo na necropsia (D. Graça: comunicação pessoal) e cedidos por esta pesquisadora, foram cortados e submetidos à reação em cadeia de polimerase (PCR) específica para gênero Leishmania, conforme metodologia descrita anteriormente ${ }^{16}$. Resumidamente, 30 cortes de fragmentos parafinados foram coletados em tubo Eppendorf utilizando navalhas descartáveis individuais para cada caso. Após retirada de parafina com dois banhos de xilol, procedeuse à extração utilizando kit comercial (Wizard Genomic kit, Promega, USA). O DNA isolado foi submetido a PCR utilizando oligonucleotídeos que amplificam a região conservada do minicírculo, e o produto amplificado foi analisado em gel de agarose $2 \%$, transferido para membrana de náilon e hibridizado com sonda de $L$. braziliensis. O exame histológico foi realizado por coloração por hematoxilina- eosina e por PAS, respectivamente para pesquisa de amastigotas e de fungos.

Foi realizada coleta de insetos com armadilhas luminosas (Shannon e tipo CDC) numa localidade na periferia de Santa Maria.

\section{RESULTADOS}

Nenhum dos 203 soros testados apresentou reatividade nos testes de imunofluorescência indireta. Os soros de cinco dos cães com títulos de imunofluorescência $\leq 1: 40$ foram não reativos, quando examinados por ELISA. O exame histopatológico e a PCR das vísceras do sexto cão, diagnosticado como positivo na necropsia, foram negativos.
Uma coleta noturna com armadilha de Shannon e duas tipo CDC, na noite de 4 de abril de 2001, numa chácara na periferia de Santa Maria, não levou à obtenção de flebotomíneos, mas apenas de alguns culicídeos. A temperatura estava abaixo de $20^{\circ} \mathrm{C}$ e havia vento forte.

\section{DISCUSSÃO}

Apesar do encontro de seis cães considerados como positivos à necropsia, cinco dos quais descritos em publicação, os presentes resultados de sorologia não indicaram a presença de leishmaniose visceral nos cães examinados.

A PCR também foi negativa em um dos cães necropsiados com suspeita de leishmaniose visceral. O teste de PCR é considerado como de alta especificidade e sensibilidade, tanto para amostras humanas quanto caninas, seja em leishmaniose visceral seja em tegumentar ${ }^{121416}$. Entretanto, apesar da pequena experiência em amostras de arquivo histopatológico ${ }^{12}$, é possível que a presente amostra possa ser um falsonegativo, pois depende da maneira como o material foi fixado $^{10}$. O exame por PCR de vísceras de cães de uma área endêmica de Minas Gerais, com a metodologia aqui utilizada, mostrou-se muito eficiente ${ }^{19}$. Santa Maria tem o segundo maior contingente militar no país e ocorre intenso trânsito de pessoal, possivelmente com cães positivos, a exemplo do que foi descrito em Natal, no Rio Grande do Norte ${ }^{11}$, e L. longipalpis já foi encontrado em província argentina próxima ${ }^{18}$. Esta espécie é bastante versátil, como mostra sua adaptação ao oeste de São Paulo ${ }^{5}$. Adicionalmente, em Mato Grosso do Sul há outras espécies suspeitas na transmissão de Leishmania chagasi ${ }^{9}$.

Deste modo, não é impossível que ocorram casos de leishmaniose visceral no Rio Grande do Sul, a depender das modificações ambientais que ocorrerem. No presente estudo, não encontramos cães infectados, 
o que indica que a leishmaniose visceral, se ocorrer em cães da região, é muito rara. Há relatos de veterinários da região de Santa Maria de uma leucemia em alguns cães, de etiologia desconhecida. A condição dos seis cães considerados como positivos precisa ser melhor esclarecida, com possibilidade de ocorrência de leishmaniose tegumentar ou de doença de Chagas.

O não encontro de flebotomíneos na coleta realizada certamente é devido às condições climáticas na época. A fauna de flebotomíneos do Estado é pouco conhecida, com relato de presença de Lu. neivai no Município de Santa Maria ${ }^{13}{ }^{15}$ e no litoral $^{8}$, de $L u$. fischeri no litoral $^{7}$ e de Lu. neivaie de outras espécies em outros municípios do noroeste do estado ${ }^{620}$, da Serra do $\operatorname{Mar}^{6}$ e do nordeste $^{8}$. Os relatos de Lu. longipalpis em Misiones ${ }^{18}$ e de $L u$. pessoai e Lu. misionensis infectados com Leishmania braziliensis no noroeste do Estado do Rio Grande do $\mathrm{Sul}^{20}$ ressaltam a importância de estudos mais completos da fauna de flebotomíneos do Rio Grande do Sul.

\section{AGRADECIMENTOS}

Dra. Eunice A. B. Galati, por chamar nossa atenção para o trabalho inicial de leishmaniose em cães em Santa Maria; à Dra. Dominguita Graça, pelas informações sobre os cães positivos e o fornecimento de material do sexto cão para exame; à FUNASA/MS (Brasília- Dr. João Batista Vieira; Florianópolis- Dra. Suzana Zeccer), pelo apoio ao trabalho de campo; ao motorista Bento José Simão, pelo apoio no decorrer do trabalho de campo; aos Drs. Reginaldo P. Brazil (CPQRR/Fundação Oswaldo Cruz) e Mauro Marzochi (ENSP/Fundação Oswaldo Cruz), pela colaboração no processamento das amostras.

\section{REFERÊNCIAS BIBLIOGRÁFICAS}

1. Andresen K, Gasim S, Elhassan AM, Khalil EA, Barker DC, Theander TG, K harazmi A. Diagnosis of visceral leishmaniasis by the polymerase chain reaction using blood, bone marrow and lymph node samples from patients from the Sudan. Tropical Medicine and International Health 2:440-444, 1997.

2. Aviles H, Belli A, Armijos R, Monroy FP, Harris E. PCR detection and identification of Leishmania parasites in clinical specimens in Ecuador: a comparison with classical diagnostic methods. Journal of Parasitology 85:181-187, 1999.

3. Ayala MAR, Bergoxc PM, Anunciação EM. Calazar (primeiro caso autóctone no Sudeste do Paraná). Jornal Brasileiro de Medicina 39:88-89, 1980

4. Cat I, Luz E, Borba AM, Cassilha A, Costa PB, Martins FL. Leishmaniose visceral autóctone no oeste paranaense. Anais da Faculdade de Medicina da Universidade Federal do Paraná 16/17:27-35, 1973/1974.

5. Costa AI, Casanova C, Rodas LA, Galati EA Atualização da distribuição geográfica e primeiro relato de Lutzomyia longipalpis numa área urbana do Estado de São Paulo, Brasil. Revista de Saúde Pública 31:632-633, 1997.

6. Dias ES, Falcão AL, Silva JE Notes on the sand fly fauna (Diptera: Psychodidae) in the State of Rio Grande do Sul, Brazil. Memórias do Instituto Oswaldo Cruz 92:329-332, 1997.

7. Di Primio R. Sobre a presença do Phlebotomus fischeri Pinto, 1926, no Rio Grande do Sul. Revista de Cursos 18:141-147, 1932.

8. Di Primio R. Os flebótomos do litoral do Rio Grande do Sul. Arquivos Riograndenses de Medicina 16:475-482, 1937.

9. Galati EAB, Nunes VLB, Rego Jr, FA, Toshiro ET, Chang MR. Estudo de flebotomíneos (Diptera: Psychodidae) em foco de leishmaniose visceral no Estado de Mato Grosso do Sul, Brasil. Revista de Saúde Pública 31:378-390, 1997.

10. Greer CE, Lund JK, Manos MM. PCR amplification from paraffinembedded tissues: recommendations on fixatives for long-term storage and prospective studies. PCR Methods Applications 1:46-50, 1991.

11. Jeronimo SMB, Oliveira RM, Mackay S, Costa RM, Sweet J, Nascimento ET, Luz KG, Fernandes MZ, Jernigan J, Pearson RD. An urban outbreak of visceral leishmaniasis in Natal, Brazil.
Transactions of the Royal Society of Tropical Medicine and Hygiene 88:386-388, 1994.

12. Laskay T, Miko TL, Negesse Y, Solbach W, Rollinghoff M, Frommel D. 1995 Detection of cutaneous Leishmania infection in paraffinembedded skin biopsies using the polymerase chain reaction. Transactions of the Royal Society of Tropical Medicine and Hygiene 89:273-275, 1995.

13. Marcondes CB, Lozovei AL, Vilela JH Distribuição geográfica de flebotomíneos do complexo Lutzomyia intermedia (Lutz \& Neiva, 1912). Revista da Sociedade Brasileira de Medicina Tropical 31:51-58, 1998.

14. Otero AC, Silva VO, Luz KG, Palatnik M, Pirmez C, Fernandes $\mathrm{O}$, Palatnik de Sousa CB. Short report: occurrence of Leishmania donovani DNA in donated blood from seroreactive Brazilian blood donors. American Journal of Tropical Medicine and Hygiene 62:128-131, 2000.

15. Pinto C. Pesquisas sobre parasitologia humana e animal no Rio Grande do Sul. Arquivos do Departamento Estadual de Saúde do Rio Grande do Sul 2:73-91, 1941.

16. Pirmez C, Silva Trajano V, Paes-Oliveira Neto M, da-Cruz AM, Goncalves-da-Costa SC, Catanho M, Degrave W, Fernandes O. Use of PCR in diagnosis of human american tegumentary leishmaniasis in Rio de Janeiro, Brazil. Journal of Clinical Microbiology 37:1819-1823, 1999.

17. Pocai EA, Frozza L, Headley SA, Graça DL. Leishmaniose visceral (calazar). Cinco casos em cães de Santa Maria, Rio Grande do Sul, Brasil. Ciência Rural 28:501-505, 1998.

18. Salomón OD, Sosa Estani S, Rossi GC, Spinelli GR. Lutzomyia longipalpis y leishmaniasis visceral en Argentina. Medicina 61:174-178, 2001.

19. Silva ES, Gontijo CM, Pirmez C, Fernandes O, Brazil RP. 2001 Short report: detection of Leishmania DNA by polymerase chain reaction on blood samples from dogs with visceral leishmaniasis. American Journal of Tropical Medicine and Hygiene 65:896-898, 2001.

20. Silva OS, Grunewald J. Contribution to the sandfly fauna (Diptera: Phlebotominae) of Rio Grande do Sul, Brazil and Leishmania (Viannia) infections. Memórias do Instituto Oswaldo Cruz 94:579-582, 1999. 